\title{
1. Resisting or embracing institutional models of parenthood: an analytical framework
}

\author{
Daniela Grunow
}

\section{INTRODUCTION}

The decision to have a child has never appeared more individualized and conscious than today, in early twenty-first century Europe. While fewer couples opt for parenthood altogether, those who do often plan the transition carefully, deliberating early-on when to start a family and how to raise their child (Balbo et al. 2013; Grunow and Evertsson 2016; Klijzing 2000). On the one hand, this trend reflects greater individual agency and gender equity among couples as pregnancy has become calculable and both sexes enter parenthood on more equal terms, usually with similar levels of educational attainment and employment experience. On the other hand, the need to carefully plan the first care-intensive years of parenthood appears more eminent today than ever before. First, the question how new mothers and fathers should adapt to their shifting obligations for childcare and work is less clear as both partners have more similar market and non-market skills than their parents' generation. In addition, more equitable care arrangements between mothers and fathers have become feasible, even during the early stages of parenthood, as more sophisticated devices for expressing breast milk and bottle-feeding have become available (Johns et al. 2013). Second, institutional shifts in gender culture and family policies have rendered gendered work-care adaptations less clear, as European societies in general favour men's more active engagement in infant care (Edlund and Öun 2016). This shift is most clearly evident in the family policy realm, as more countries are making care leaves available to fathers and offer incentives for dual care. Consequently, mothers' all-encompassing role as sole primary carers has become less entrenched. Third, employment interruptions and lower work hours to enable care by either parent put a strain on the household budget during a time when families need more rather than less financial security. Most families nowadays depend on two incomes to maintain 
their standard of living (OECD family database 2017). At the same time, costand time-intensive approaches to parenting, for example intensive parenting, have become widespread in Europe (Grunow et al. 2018; Wall 2010). New parents thus need to carefully evaluate the present and future costs and benefits of the time they spend in paid work versus caring for their child (see Nitsche and Grunow 2018). Not least for mothers these evaluations include weighting forgone employment against social norms of intensive care. Work-related costs and benefits have been found to go beyond adjusted work hours and loss of income during employment interruptions related to parenthood. In particular, motherhood penalties and fatherhood premiums in hourly earnings have been shown to be long-term and in part unexplained by changes in mothers' and fathers' employment behaviour or work commitment (Budig et al. 2010; Cooke 2014; Hodges and Budig 2010; Killewald 2012).

At present, despite these trends, which would predict more gender-equal arrangements of earning and caring, most mothers, but few fathers, adjust their employment in favour of childcare and continue to frequently accept negative career consequences of parenthood, including financial dependence on the welfare state or their partner. We refer to this gendered pattern as 'normative', as it reflects an orientation towards gendered separate spheres of (predominantly female) caring and (predominantly male) earning (Davis and Greenstein 2009). In contrast, we refer to arrangements in which parents work and/or care jointly to an extent that would be considered uncommon in a particular context as 'non-normative'. The question of how these normative and non-normative processes unfold over time and how gendered choices, beliefs and ascribed traits on the macro and micro levels of societies interact is still unclear and will be investigated in this book.

We aim to understand the transition to parenthood through couples' own subjective experiences, from before the birth of their first child to after. Our focus is on the accounts of dual-earner couples who have the least to lose and potentially the most to gain from a more gender-equal division of paid work and care during the early stages of parenthood. The accounts analysed in this book are thus not statistically representative of new parents in a given institutional context (see Chapter 3). They mostly reflect the views and experiences of the better educated and more privileged new parents in their country, as these are the couples whom we expect to be at the forefront of renegotiating gendered transitions to parenthood (Grunow and Veltkamp 2016).

In the volume preceding this one we asked why couples living fairly egalitarian lives would consider adopting traditional, normative gender practices upon entering parenthood (Grunow and Evertsson 2016). More than 150 dual-earner couples, who were parents-to-be at the time, shared their plans and expectations about the future with us. We learned of their beliefs concerning motherhood and fatherhood, their plans for the provision of care 
for their unborn child and their strategies for their future as working parents. Even though many of these couples had reasons to consider non-normative work-care arrangements, surprisingly few planned to adopt them.

In this present volume, we visit the couples for the second time, between six months and two-and-a-half years after their child has been born and parenthood has become an everyday reality for them. Our analytical focus is on the couples who planned for a non-normative division of labour after the transition to parenthood. We compare their experiences to those of their peers with more conventional work-care plans and assess whether the parents' plans expressed during pregnancy have been realized and if not, why this is the case and how the mothers and fathers feel about this. How do the non-normative couples who were able to realize their plans (un)do gender in everyday practice and how do they construct this in terms of their own identity and agency? Do they face different objective and subjective challenges in comparison to their more normative peers in other country contexts?

The couples who shared their experiences of early parenthood with us have been recruited in selected institutional contexts: Sweden, Germany, Austria, Switzerland, Italy, Spain, Poland and the Czech Republic. Via their institutions, these countries promote different degrees of joint earning and caring and provide various levels of support for working and caring families. In the volume preceding this one we have learned that national gender cultures and family policies address parenthood in sometimes contradictory ways (Grunow and Evertsson 2016). These contradictions were mirrored in nascent parents' beliefs and plans. In the present volume, we analyse how couples in these diverse and sometimes contradictory contexts resisted or embraced the various competing institutional and normative models of parenthood and how these processes entered the couples' narratives. The chapters assembled in this edited volume will place a specific analytical focus on new mothers and fathers who during pregnancy expressed an intention to resist normative patterns of traditionalization and realize a division of work and/or care that would be considered non-normative in that particular institutional context. We investigate which couples have been able to realize such non-normative divisions of care and paid work, which couples haven't, and which forces they emphasized as important during this process. We examine whether the couples (not) realizing their non-normative work-care plans had similar or different experiences compared to their peers. The stories of their experiences during the early phase of parenthood will be at the heart of this second edited volume.

While raising children is important for parents and children under normative and non-normative conditions alike, it is also vital for the well-being of societies and welfare states in general. European welfare states depend fundamentally on families' balancing paid and unpaid work with reproduction and care to keep societies functioning. During industrialization and the period 
thereafter, developing welfare states in Europe framed reproduction and care work almost exclusively as families' private concerns. Due to this, resulting policies fostered (or took for granted) strong gender divisions of labour, reproducing power differences to the disadvantage of women. The increase in women's educational and occupational attainment in the second half of the century challenged this, leading to changed divisions of labour not only between women and men within families but also on other societal levels. While women took on more paid work, the unpaid work (including childcare) was mostly redistributed from the family to the market or the state, with this redistribution varying substantially between national contexts. Over the past decades, parenting has increasingly become a focus point for policy makers and their expert advisors (Lee et al. 2014). Policy makers and welfare states thus profoundly shape individual expectations and experiences of parenthood and early childhood, not least through family policies, gender culture ${ }^{1}$ and the interplay between the two (Grunow and Evertsson 2016). To capture this variation, our interviews have been carried out in eight institutional contexts with varying levels of practical and ideological support for working parents, care-oriented fathers and career-oriented mothers.

\section{ANALYTICAL LAYERS ADDRESSED IN THIS BOOK}

This book combines three analytical perspectives that are essential for elucidating under which conditions new parents resist or embrace institutional models of parenthood: the couple perspective (which acknowledges that individual experiences of motherhood or fatherhood can only be properly understood by linking them to the experiences of their partner), the transition perspective (which focuses on how plans and experiences of parenthood form and change over time) and the institutional perspective (which emphasizes the fact that transitions to parenthood are socially constructed processes and need to be understood in relation to their particular institutional context).

First, the couple perspective helps to illuminate the ways in which individual experiences of parenthood and parenting-choices are tied to the plans and choices of the other parent (Elder 1998; Moen and Erickson 1995). We assess how couples with non-normative work-care plans negotiate and frame work and care during the early stages of parenthood and explore the diverse strategies new mothers and fathers use to cope with this life course transition. The couples interviewed for this volume are mostly middle-class, reflecting our theoretical interest in dual-earner couples with similar educational levels (for a detailed discussion see Grunow 2016 and 2017). From a theoretical point of view, the accounts of these well-educated dual-earner couples promise to be especially insightful, reflecting how new parents weigh their own gender ideologies and work-care preferences against institutionalized social parenting 
norms and financial concerns. In this volume, we hear the stories of ambitious and career-oriented new mothers who manage to boost their career in the midst of pregnancy and birth, pushing their less career-committed partners to support them (for instance in the Polish case). We learn of the male partners' attempts to cope with this situation, which in some cases deviates from their own original plans and even may challenge their family ideals. We hear stories of disappointment faced by other career-oriented mothers who find themselves put on the mommy track by their bosses while their partners' career remains unaffected by parenthood (for instance in the Italian case). We hear stories of mothers feeling discriminated at work but hanging in there, due to their partner's unemployment (for instance in the Swiss case). We also see new mothers who re-evaluate their initial ideal of being a working mom, feeling let down by their absent, breadwinning partners, who themselves feel entitled to leave housework and care to the mother (for instance in the German and Czech cases). By focusing on couples planning a non-normative transition to parenthood, while comparing their experiences and concerns to those of their peers who had more conventional normative plans and pathways into parenthood, the institutional models of parenthood become visible in this volume.

Second, the transition perspective allows us to focus on change over time and the ways the couples realize or adapt their pre-birth plans and expectations to the everyday realities of parenthood. Our analyses show that most couples planned to take up a less equitable division of paid and unpaid work after the birth of their child, reflecting a dominant normative pattern in all countries apart from the Swedish and Polish couples interviewed. The couples' accounts during pregnancy echoed gendered parenthood ideologies, at times fundamentally resting on deeply rooted beliefs in maternal instinct and a mother's biological capabilities being superior to a father's, but also sometimes explicitly challenging these beliefs (Evertsson and Grunow 2016). In this volume, we show that such beliefs about motherhood and fatherhood sometimes differ quite markedly from new parents' actual experiences of motherhood and fatherhood. We learn how difficult it can be for working mothers to balance their paid job with care work in countries such as Spain, which offer a rather short paid care leave, or in countries such as the Czech Republic and Poland, which lack institutional support for early childcare. We hear new fathers describing how hard it is for them to live up to their partner's expectations of being present for the child and the relationship, on top of their full-time earner role. We also learn of men whose accounts reflect being basically unaffected by parenthood, for instance in Italy, Switzerland and Germany, while their female partners find their world turned upside-down. Our evidence suggests that the beliefs and expectations informing pre-birth plans are shaped by the dominant gender culture and parenting ideals in the given context, with these often being counterbalanced by everyday realities and practical concerns after 
the arrival of the child. We explore the adjustments that couples make to their own narratives over time, based on their actual lived realities.

Third, this book provides information on the ways in which the institutional context structures transitions to parenthood and concomitant gender divisions of paid work and care in each of the eight nations. Although parents' plans were often based on their interpretations of gender culture and family policies as signalling socially accepted ways of (gendered) parenting and work-care arrangements, these institutional points of reference usually remained implicit in the individual narratives. Instead, the parents referred to practices or expectations expressed by relevant others, including fellow parents, friends, relatives and colleagues as influencing their work-care plans. The clear institutional models underlying these individual stories came to the fore when comparing couples' narratives within and across countries and often went unnoticed by the couples themselves (Evertsson and Grunow 2016). We take the cross-national analysis one step further by investigating under which conditions couples retained their pre-birth beliefs and plans. We find that these plans have proven more feasible the better they corresponded with the institutional context. For the Swedish couples represented in our edited volume, for instance, plans of joint earning and caring were rather easy to realize, while the Polish couples committed to joint earning and caring reported struggling substantially with the practical aspects of shared parenthood, often at the expense of relationship quality. German non-normative couples reported less difficulties with the practical aspects of realizing shared work or care arrangements but emphasized suffering from negative judgements by relevant others; especially for violating norms of intensive mothering and primary maternal care. In the volume preceding this one, we showed that national gender culture may or may not fit well with existing family policies. We referred to this phenomenon as a policy-culture gap (Grunow and Veltkamp 2016). For the analyses presented in this volume, we demonstrate that smaller policy-culture gaps (such as in egalitarian Sweden and the gender essentialist Czech Republic) better enable pre-birth plans to become post-birth realities. We also find that an alignment between plans before the birth and realities after was easier to achieve for couples whose pre-birth plans already fit the normative institutional models of parenthood, while parents (in particular mothers) committed to non-normative work or care strategies had to continually swim against the current and faced high emotional costs, including increased stress and feelings of guilt. 


\section{THEORETICAL FOCUS: UNDERSTANDING COUPLE-DYNAMICS DURING THE TRANSITION TO PARENTHOOD}

The transition to parenthood is often considered to mark a turning point in the life course (Clausen 1995; Nitsche and Grunow 2016), altering not only everyday practices and patterns of conduct in fundamental ways, but also imposing a need to reconsider life priorities as new parents adapt to their shifting obligations as carers of an infant, in addition to their other social roles, in particular their work roles. Mothers are, however, more likely than fathers to consider their transition to parenthood a turning point in their lives (Rönkä et al. 2003). We aim to assess how this finding may relate to the complex ways in which gender and family formation are intertwined. Following Elder (1998), we draw on the notion of subjective experiences of parenthood as a turning point over the life course, which has the power to disrupt established patterns and paths, such as established divisions of paid and unpaid work within couples as well as individual employment trajectories. Within couples, individual trajectories across the domains of family formation and work are linked to those of the partners', influencing individual behaviours and future developmental paths (Elder 1998; Moen 2003). Couples enact agency by choosing their trajectories, but such choices are always context-bound and thus constrained (Elder 1998; England 2016). Direct constraints make certain plans and choices impossible or infeasible, given a person's social position, for instance, as a new mother in comparison to a new father. Indirect constraints first change an individuals' personal characteristics (for example skills, identities or preferences), which then affect individual plans and choices (England 2016). During the transition to parenthood, both types of constraints are at work, shaping the "micro politics" (Miller 2011, p. 1095) of fathers' and mothers' intentions, plans and actions.

Based on micro theoretical perspectives on the gender division of paid and unpaid work, fathers' and mothers' intentions, plans and actions are often considered a function of both partners' relative economic resources (see Gupta 2007 for a review) and gender ideologies (see Davis and Greenstein 2009 for a review). Economic resources affect the power-balance within couples and, in addition, determine degrees of freedom couples enjoy in organizing paid work and care in line with their plans and preferences (Blumberg and Coleman 1989; Fox 2009). During pregnancy, gender ideologies, most importantly constructions of motherhood, were frequently found to override economic considerations (Evertsson and Grunow 2016). Both aspects, economic and ideological, appeared to be related to the institutional setting in which intentions and plans were formed and enacted. The relevant institutional setting 
included social norms of motherhood and fatherhood, welfare state support for working families, and the fit between the two. The country chapters assembled in this volume analyse how economic and ideological considerations enter the couples' narratives after the birth of their first child and to what extent they contain direct or indirect references to the institutional context. Next to these theoretically derived (and empirically confirmed) themes, we address the empirically derived themes which came up in the first round of interviews conducted during pregnancy: the process of forming a motherhood identity, the process of successfully creating a fatherhood identity beyond the family provider role, and the conflation of biological or physiological differences between mothers and fathers (especially breastfeeding) with associated stereotypical gendered work-care ascriptions (Evertsson and Grunow 2016). These themes appeared to be relevant to many of the couples during pregnancy. Clearly, gendered references to these themes illustrated how both direct and indirect constraints varied for fathers-to-be compared to mothers-to-be. In this present volume, we re-assess these themes, based on couples' narratives after their child has been born.

\section{Re-assessing the Gendering of Finances}

In the previous edited volume, we learned that during pregnancy, when planning for the time after birth, couples attached gendered meanings to the way they rationalized their finances and to their own gender ideologies, in light of context-specific social norms (for a more detailed cross-national analysis see Evertsson and Grunow 2016). In couples where the men had higher earnings or better career prospects than their female partner, financial concerns were frequently raised as explanations for why couples planned a gendered, normative transition to parenthood. This is in line with the mechanisms emphasized by economic theory (Becker 1981; Blood and Wolfe 1960; Lundberg and Pollak 1996). However, in couples where the female partner had the higher earnings or better career prospects (referred to as non-traditional resource matches hereafter), accounts frequently emphasized the transition to motherhood as an overwhelming 'natural' process that rendered the couples' financial concerns unimportant. In these couples, expectant fathers often presented themselves largely as (future) family providers, even if they were not at the time of the interview (this was especially the case in Italy and the Czech Republic, see Evertsson and Grunow 2016, p. 276). In addition, some couples downplayed the woman's objectively better employment position. Other couples with non-traditional resource matches stated openly that financial concerns were a reason for them to discard plans for a normative transition to parenthood, in line with economic theory. Based on these earlier findings, we aim to assess in the present volume whether the gendering of financial resources during preg- 
nancy has remained stable after the transition to parenthood and how this has affected the new mothers' and fathers' employment behaviour while caring for their new-born.

Among the couples with non-normative work-care plans during pregnancy were many with rather similar skills and earnings, as well as a few with non-traditional resource matches. The accounts of these couples most openly challenged ideologies of superior and 'natural' motherhood during pregnancy; many of them emphasizing the importance of fairness and equal involvement in the care of their infant. Some of these accounts revealed rather strong disapproval and normative sanctioning by relevant others towards the mothers' planned early return to employment and their reduced availability as maternal carers for the child. In contrast, planned paternal involvement in childcare appeared to be mostly socially approved, while planned violation of the paternal family provider role was frequently problematized. For the couples who planned non-normative work-care divisions, these findings point to constraints arising from the social ascription of male earning and female caring during the transition to parenthood. In the analyses presented in this volume, we examine how the couples negotiated this misfit between their own ideologies and plans, and the dominant social parenthood norms. Among the couples who realized their non-normative plans, we were also able to observe different (less gendered) processes of paternal and maternal bonding.

\section{Re-assessing the Transformation of Identities and Biology}

Among the interviewed couples with normative work-care plans during pregnancy, many women expressed experiencing (or expecting to experience) a 'natural' transformation of their personal identity with their transition to motherhood (Evertsson and Grunow 2016, p. 274f.). This maternal identity would provide them with the altruism and knowledge needed to fully devote themselves to the care of their child (Ibid.). Among those with less normative work-care plans, resisting this transformation was an issue, as a dominant motherhood identity was expected to hinder the father's bonding with the child and the mothers' return to employment. In contrast to the maternal identity, the paternal identity was expected to be created over time through symbolical acts and rituals, for instance by fathers giving the child the evening bath (Evertsson and Grunow 2016, p. 278). Especially among fathers with normative or unclear work-care plans during pregnancy, development of a paternal identity remained vague. In this present volume, we find out whether and how the theme of changing identities was brought up again in the new parents' accounts and how the accounts varied between mothers and fathers.

Finally, we reassess how biological (or physiological) aspects of motherhood and fatherhood continued to be interwoven with gender divisions of work 
and care. Pregnant couples emphasized the relevance of breastfeeding as an ideal and justification for planned normative work-care divisions after childbirth. In this volume, we assess whether different feeding strategies applied after childbirth served as a cause for, or were consequence of, constraints to the couples' preferred division of work and care.

\section{INSTITUTIONAL CONTEXT, POLICY-CULTURE GAPS AND (NON-)NORMATIVE WORK-CARE PLANS}

We argue that individual plans and experiences of parenthood are influenced in direct and indirect ways by the institutional context, most importantly the gender culture, work-family policies and their mutual institutional fit (policy-culture gaps). In the volume preceding this one, we looked at and compared several dimensions of the institutional contexts which operate in the cultural and policy realms, including the promotion of fathers as carers and the promotion of mothers as earners. The former addresses the extent to which fathers are institutionally framed as potential carers for their infants, in addition to their earner role. The latter captures working mothers' supported defamilialization through childcare provision for infants and toddlers, supported familialism through long paid leaves and cultural support for maternal employment (Grunow and Veltkamp 2016). ${ }^{2}$ These dimensions have been found to be salient in informing pregnant couples' joint future work-care plans. Consequently, the dimensions may also be useful for understanding why and how what we consider 'non-normative' plans and work-care divisions in this volume differs between countries.

Table 1.1 summarizes the main findings of our earlier edited volume and complements them with the country-specific definitions of non-normative work-care plans applied in the following chapters. ${ }^{3}$ The first dimension addresses fathers as providers of infant care, in addition to their traditional primary earner role. In the work-family policy realm, this dimension is reflected by the number of days of paid care leave provided for fathers, in particular paternity or parental leaves, and the share of care leave reserved for fathers (if any). The policy data come from the Multilinks Database (Keck and Saraceno 2012) and refer to the year 2008, representing, with the exception of Germany and partly Italy, the work-family policy frameworks in place when the couples interviewed for this edited volume were expecting their first child. ${ }^{4}$ The label 'strong' is applied when the fathers' reserved share is at least two months and paid at 60 per cent or more of foregone wages (Grunow and Veltkamp 2016, p. 20). The label 'medium' is applied when the leave is paid, but no quota is reserved for fathers or when the share that can be claimed by fathers is high, but financial compensation low (Ibid.). In countries with 


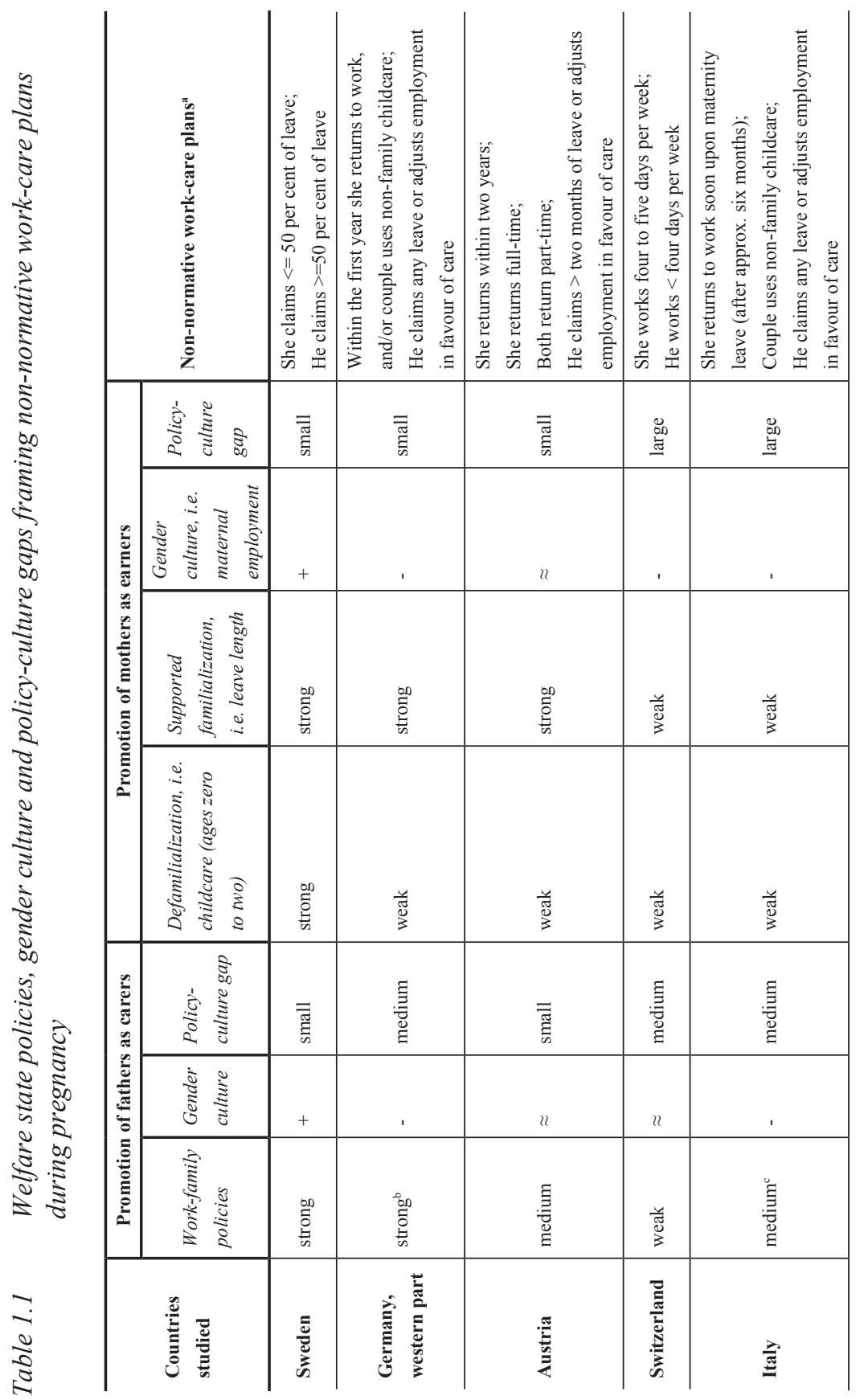




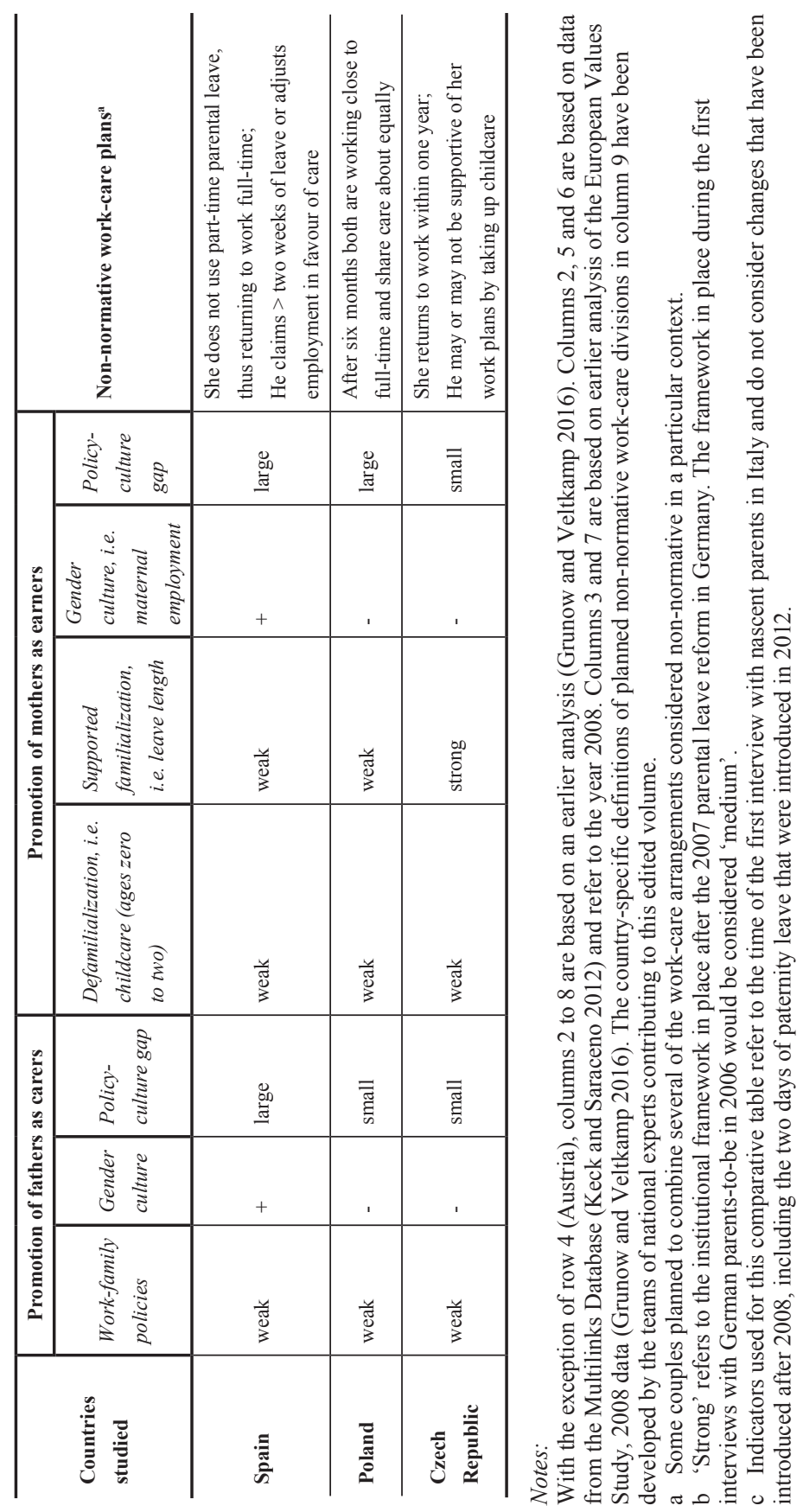


neither a quota nor significant financial compensation, the promotion of fathers as carers is classified as 'weak' (Ibid.).

Research shows that paid parental care leaves with a duration shorter than or up to six months (the period during which the World Health Organization recommends exclusive breastfeeding) will usually be completely taken by the mother, unless there is a leave quota (Evertsson and Grunow 2016). Consequently, policies are unlikely to promote fathers as providers of infant care if they are based on short overall parental leaves (six months or less). At the cultural level, the promotion of fathers as carers is reflected in widespread attitudes in society towards men as carers, frequently measured by (dis)agreement with statements such as 'In general, fathers are as well suited to look after their children as mothers' and 'Men should take as much responsibility as women for the home and children' (EVS 2011). The gender culture assessments presented in Table 1.1 are based on analyses of the 2008 European Values Study (data was collected shortly before the in-depth interviews analysed in this volume were conducted). Using weighted nationally representative samples we assess whether respondents in a particular country supported egalitarian gender ideologies on average more $(+)$, less (-) or to about the same degree $(\approx)$, compared to the European mean (see also Grunow and Veltkamp 2016). ${ }^{5}$ The policy-culture gaps indicate how well the respective policies reflect the dominant gender culture in a country. Please note that, 'small' policy-culture gaps do not necessarily imply that fathers are effectively promoted as carers. ${ }^{6}$

The second dimension displayed in Table 1.1 concerns the promotion of mothers as earners. In the policy realm, this includes the provision of early childcare (as a key measure of mothers' defamilialization) and effective paid parental leaves (signalling working mothers' supported familialism; see Saraceno and Keck 2011). The promotion of mothers as earners is labelled 'strong' in countries with early childcare coverage (ages zero to two) above 60 per cent, 'medium' with a coverage between 30 and 60 per cent and 'weak' with a coverage below 30 per cent (Grunow and Veltkamp 2016, p. 20f.). Measures of supported familialism are labelled 'strong' when the maximum effective leave period is at least 52 weeks, 'medium' when the leave is between 26 and 51 weeks, and 'weak' when it is below 26 weeks (Ibid.). Research shows that early childcare and medium length care leaves foster mothers' labour market attachment and minimize wage penalties while long leaves may have the opposite effect (Aisenbrey et al. 2009; Ruhm 1998; Rønsen and Sundström 2002). At the cultural level, support for maternal employment is measured in terms of (dis)agreement with the statements 'A working mother can establish just as warm and secure a relationship with her children as a mother who does not work' and 'A pre-school child is likely to suffer if his or her mother works' (EVS 2011). Policy-culture gaps concerning the promotion of mothers 
as earners are considered 'large' if cultural support for maternal employment is weak and supported familialism is also weak. In this constellation, families lack financial alternatives to mothers' paid work, even though their participation in paid work would violate social norms. Gaps are considered 'small' when cultural support for working mothers is weak and supported familialism strong or cultural support for working mothers is strong and defamilialization is strong. In these latter constellations, policies enable new families to better realize culturally prescribed paths of parenting.

Turning to the countries compared in Table 1.1, Sweden displays a strong institutional framing of fathers as carers and mothers as workers and the policy-culture gaps are considered small (see also Grunow and Veltkamp 2016). In the policy realm, support for fathers as caregivers is provided via well-paid parental leaves which include a two month leave quota reserved for fathers (respectively the parent who would otherwise not take any leave). Working mothers and fathers have equal access to, in total, close to 16 months of paid parental leave. This period overlaps with children's right to a childcare place from the age of one. Consequently, paternal engagement in infant care and maternal employment (interrupted by parental leave) have become a norm, as is reflected in Swedes embracing paternal care and maternal employment on average more strongly than their European peers (indicated by the plus sign in Table 1.1). Couples planning to share care leave about equally or the father planning to take more leave than the mother would be considered non-normative, signifying that even in Sweden truly equitable work-care divisions are still exceptional. Among the twenty couples interviewed for the Swedish study, twelve reported such non-normative work-care plans and eight couples realized them (see Chapter 2, Table 2.1 and Chapter 4).

Today, in Germany, policy support for fathers as carers is almost as strong as in Sweden. This is due to the 2007 parental leave reform which included a leave quota similar to the Swedish one. ${ }^{7}$ The couples analysed in this edited volume lived in the western part of Germany and have been interviewed right before (during pregnancy) and after the 2007 policy changes (when their child was around one year old). Because their child was born before the reform, the parents were not entitled to the new regulations. Please note that the analysis of gender culture presented in Table 1.1 (displayed in columns 3 and 7) is restricted to respondents from western Germany, due to continued cultural differences between eastern and western Germans (Grunow 2014). In 2008, when the gender culture data were collected, cultural support for caring fathers was weaker in the western part of Germany than the European average, indicating a medium policy-culture gap concerning paternal care for the couples analysed in this edited volume (Table 1.1). Support for mothers as workers consistently mirrored familialism, as job-protected leaves were (and still are) long (up to three years) and transfers, such as tax splitting and 
child allowance, promoted extended phases of maternal homemaking. At the time of our interviews childcare support for infants and toddlers was still low (though it has been developed extensively over the last decade), implying that small children should be cared for at home. The ideal of maternal home care is mirrored by the fact that cultural support for maternal employment is below the European average (see Table 1.1). Hence, we consider policy-culture gaps for mothers as workers small, consistently pointing to familialism. At the time of the qualitative interviews with the German parents included in this volume, mothers returning to work 'early' (within the first year after childbirth) and couples using non-family childcare during the first year would be considered non-normative. Fathers claiming any parental leave or engaging in care at the expense of paid employment would also be considered non-normative in the western part of Germany where our interviews took place (Table 1.1). Eight out of the fourteen German couples analysed in this edited volume expressed and realized non-normative work-care plans along these lines (see Chapter 2, Table 2.1).

In Austria, policy support for fathers as carers is slightly lower than in Sweden and Germany while cultural support corresponds to the European average (Table 1.1). Employed parents are entitled to claim job-protected parental leave of up to two years, of which one month can be shared. Entitled parents may take turns, each with a minimum leave duration of two months at a time (for a detailed policy description see Schmidt et al. 2015). An additional childcare allowance is available, offering five different payment and duration options, including an option to prolong the payment of the childcare allowance by six months (up to three years), conditional on the father claiming at least two months of the parental leave time. Support for mothers as workers was comparable to Germany in 2008, thus reflecting supported familialism, both culturally and policy-wise. This includes limited availability of early childcare and long financially compensated parental leaves (up to three years if shared with the father). The Austrian system of parental leave and childcare allowance is mainly used by mothers. In comparative perspective, we consider policy-culture gaps concerning fathers as carers and mothers as workers small. In our study, Austrian coupes are considered planning non-normative work-care arrangements if the father claims more than two months of parental leave or reduces his working time. Another non-normative work-care arrangement would be applied among couples in which mothers return to work full-time and/or within the first two years of their child's life. Among the couples interviewed for the Austrian study, eight out of eleven couples planned to adopt one or several combinations of these non-normative work-care arrangements. Five of these couples realized a non-normative arrangement (see Chapter 2, Table 2.1). 
Switzerland offers no policy support for fathers as carers (Table 1.1). Paid leave is short in comparative perspective and not accessible for fathers, despite increasing public debate on paternal leave (Valarino 2016). Cultural support for caring fathers corresponds to the European average, resulting in medium policy-culture gaps in the sense that fathers are not institutionally framed as carers. In contrast, policy-culture gaps for mothers as workers are considered large, for two reasons. First, public support for early childcare is weak and so is maternity leave, given the extremely short paid leave period (14 weeks) available to new mothers. ${ }^{8}$ Second, even though the state offers little financial or practical help to working and caring parents and thus no alternative to dual earning, cultural support for working mothers is low. Continuous dual earning is thus frequent, with fathers working full-time and mothers part-time, while dual caring is not. The term "modern family traditionalism" (Levy et al. 2002) has been used to label the dominant Swiss work-care arrangement. Non-normative work-care plans include arrangements in which the mother works four to five days per week and/or the father works less than four days per week. Among the 11 couples analysed in this edited volume, four planned and realized a non-normative work-care division (see Chapter 2, Table 2.1).

In Italy, the institutional framing of fathers as carers is mixed. The parental leave reserves, at most, six months for the mother and six months for the father and can be used for a total of ten months (six of which are paid at 30 per cent of pre-birth earnings). If the father is taking at least three months of leave, eleven months can be used in total. Because only six months of parental leave are paid, usually the mothers claim the paid share right after maternity leave and the fathers do not claim any (Naldini and Jurado 2013). An additional so-called 'breastfeeding leave' exists, which allows for a working time reduction for the mother or the father. We consider policy support for fathers as carers medium, not strong (Table 1.1), given the low level of financial compensation. Cultural support for caring fathers is below the European average and thus weak, resulting in a medium policy-culture gap. For Italian mothers, we consider this gap to be large because childcare support is lacking, paid leave is comparatively short (though longer than in Switzerland) and cultural support for maternal employment is low. Against this background, Italian parents are considered to plan non-normative work-care arrangements in cases where mothers plan to return to work soon after maternity leave (after approximately six months) and/or fathers plan to claim any leave or to adjust their work hours in order to spend time caring for their child. In addition, couples planning to use non-family childcare to facilitate the mother's return to work are considered non-normative. Four out of the twenty-two couples interviewed for this edited volume reported planning and realizing one or more of these non-normative arrangements (see Chapter 2, Table 2.1). 
Turning to Spain, we consider policy-culture gaps equally large for both caring fathers and working mothers (Table 1.1). Spain offers new fathers two weeks of paid paternity leave but no reserved parental leave quota. The parental leave is long (up to 34.5 months) but unpaid and thus difficult to afford for working parents. Mothers thus frequently use parental leave to at least reduce their work hours while fathers refrain from claiming any leave. On average, cultural support for caring fathers and working mothers is high (as high as in Sweden). Against the rather unsupportive family-policy background, non-normative work-care divisions include couples in which the fathers-to-be had made explicit plans to provide infant care. This included him claiming parental leave for at least two weeks or adjusting his working time to provide infant care. In addition, mothers not claiming any (part-time) parental leave and thus returning full-time following the obligatory three months of maternity leave are considered non-normative in the Spanish case. Among the couples analysed in this edited volume, during pregnancy six out of fifty planned to adopt one or more of these non-normative arrangements during the early stages of parenthood. Four of these couples realized a non-normative transition (see Chapter 2, Table 2.1).

In Poland, both policy and cultural support for caring fathers is weak, resulting in a small policy culture gap. During the time when the interviews were conducted, employed fathers were entitled to one (2011), respectively two (2012), weeks of paid paternity leave. Similar to Spain, parental leave is long but unpaid in Poland and thus not an option for most fathers or mothers. In Poland, working mothers and fathers receive little institutional support to balance care with dual employment and the fact that part-time work is rare makes this reconciliation even more difficult. Maternity leave was paid and lasted six months during the first wave of interviews with the Polish parents (in 2011) and was more recently prolonged to twelve months. For the couples represented in this edited volume, we thus consider the policy-culture gap concerning maternal employment to be large. In the Polish context, many new mothers drop out of the labour market temporarily, due to lack of support structures (OECD family database 2017). Maternal employment interruptions of three years or more after childbirth would be the common and normative pattern (Matysiak and Vignoli 2010). In this context, non-normative work-care plans include both partners returning back to work (close to) full-time after six months and fathers' about equal involvement in childcare. In spite of the institutional background, the couples recruited for this study were remarkably devoted to living non-normative work-care divisions (Reimann 2016). All of the twelve couples interviewed during pregnancy planned to maintain non-normative dual-earner and dual-carer arrangements (see Chapter 2, Table 2.1). Although all realized a non-normative transition to parenthood, they struggled hard to reach divisions of paid and unpaid work they considered fair. 
In the Czech Republic, the institutional framing of fathers as carers is weak, as neither policy makers nor society demand or support paternal involvement as carers for their infants. Czech fathers have no statutory entitlement to paternity leave. They could, in principle, claim some of the paid maternity leave though (Evertsson 2016, p. 60). Czech mothers are entitled to very long paid care leaves (up to four years), allowing them to take care of their children for an extended period of time. This policy matches to some extent the lack of cultural support for working mothers (Table 1.1). In addition, previous research on the Czech couples indicates that both mothers-to-be and fathers-to-be unanimously embraced gendered and normative transitions to parenthood, with very little evidence pointing to mismatch (Nešporová and Horňáková 2016). Consequently, we consider the resulting policy-culture gaps concerning the promotion of mothers as earners and fathers as carers small. ${ }^{9}$ Couples in which the woman intended to return to work within the first year after childbirth would be considered non-normative in the Czech context. Fathers supporting such plans by taking up childcare would be rare and even more non-normative. In the Czech case, seven out of sixteen couples indicated non-normative work-care plans and five realized such plans (see Chapter 2, Table 2.1).

Taken together, the cross-national comparison highlights the wide range of European welfare states observed in this volume, beginning with social democratic, defamilialized Sweden, then turning to the traditionally conservative and increasingly dual-carer-friendly welfare regimes of Germany and Austria and then to the more ambivalent liberal-conservative Swiss regime, exemplifying extremely weak support for dual-earner parents. Turning to Italy and Spain, we also see limited support for working families in a welfare state implying "familialism by default" (Saraceno 2010, p. 33). Finally, Poland and the Czech Republic represent young and developing welfare states which after decades of post-communism institutionally display a shift towards re-familialization (Lück 2005). To be sure, whether, and to what extent, these contexts institutionally framed fathers as potential carers and mothers as potential earners influenced mothers and fathers jointly, as couples. However, due to men's and women's differential social positions in society (England 2016), couples' joint work-care solutions often came with markedly gendered consequences, as will be illustrated in the following chapters.

\section{STRUCTURE OF THIS BOOK}

This chapter has laid out the analytical framework underlying this book. Following this logic, the structure of this volume facilitates comparing transitions to first-time parenthood both cross-nationally and in-depth within their specific institutional setting. The chapters can thus be read either individually, successively, or by picking selected chapters for comparative purposes. The 
second chapter discusses the data, methods and analyses employed in the volume and provides an overview of the longitudinal data gathered first, during pregnancy and second, during the early stages of parenthood. The third chapter provides statistically representative evidence of how the rather privileged socioeconomic group to which most of the couples included in this edited volume belong, differs from their less educated and lower earning peers within countries, with respect to their gender ideologies and maternal labour force attachment. The following eight chapters are country-specific case studies and are ordered according to their institutional frameworks. Each chapter provides detailed information on the subjective accounts of the interviewed couples, focusing on couples with non-normative work-care plans, as well as the specific institutional conditions which framed the couples' individual experiences of parenthood. The countries serve as examples of different types of welfare states and gender regimes. We begin with the Swedish couples and institutional setting as an example of a social democratic welfare state that has fostered dual earning and caring for decades (Chapter 4). The Swedish chapter is followed by three studies of countries that traditionally served as examples of conservative welfare states, also known as one-and-a-half earner regimes (see Morgan 2006): Germany (Chapter 5), Austria (Chapter 6), and to a lesser extent, Switzerland (Chapter 7), which is sometimes considered a hybrid between conservative and liberal welfare regimes (Bühlmann et al. 2010). Over the past decades these countries have adopted different institutional responses to the needs of dual-earner parents and this is also reflected in the couples' narratives. In the Italian and Spanish chapters (Chapters 8 and 9), we see examples of institutionally unsupported familialism (Saraceno 2010), characteristic for the welfare state development in southern Europe. The last two country chapters reflect the institutional conditions in two former socialist countries, which are now young and developing welfare states; Poland (Chapter 10) and the Czech Republic (Chapter 11). The couples interviewed in these two institutional contexts differ markedly in their plans and struggles, as the Polish couples were committed to western ideals of equal sharing under conditions of limited welfare state support while their Czech peers tended to embrace ideals of primary maternal care, institutionally supported by long paid maternity leave. The final chapter of the book (Chapter 12) presents a comprehensive cross-national comparison of the country-specific findings and draws conclusions based on the longitudinal evidence presented in the previous chapters. The chapters presented in this book explicitly trace the links between couples' plans and gendered beliefs on the one hand, and the institutional frameworks which constrain or encourage certain plans and practices on the other. 


\section{ACKNOWLEDGEMENT}

The research leading to these results has received funding from the European Research Council under the European Union's Seventh Framework Programme (FP/2007-2013) / ERC Grant Agreement no. 263651.

\section{NOTES}

1. We conceptualize gender culture as a multidimensional social structure, which is embedded in the individual, interactional and institutional layers of a society (Risman 2004). Gender culture reflects "fundamental cultural values that together construct the idea of the "ideal" family form" (Pfau-Effinger 2012, p. 533). The gender culture thus offers new parents powerful, context-specific guidelines for the gendered division of work and care. These guidelines have been found to sometimes align, and other times conflict with existing policy frameworks and new parents' own gender ideologies (Grunow and Evertsson 2016).

2. Decommodification is understood as the degree to which a person is (in)dependent from their own paid work in order to satisfy basic material needs (Esping-Andersen 1990, 1999; Orloff 2003). Decommodification may be attained through access to resources provided by other family members (often the partner) or by the state (that is through transfer payments). State-provided childcare and support for maternal employment are labelled 'defamilialization policies'. Policy incentives for the provision by other family members are labelled "supported familialism" (Saraceno 2010, p. 34).

3. The country-specific definitions of planned non-normative work-care divisions have been developed by the teams of national experts contributing to this edited volume. During the early stages of framing this edited volume these experts had been asked to define and explain which plans expressed by parents-to-be during the first round of interviews would be considered non-normative in their country, given standard practices and what would be considered the norm. To be sure, these non-normative constructions often remained far from egalitarian divisions of work and care, as they concerned the mothers' roles more extensively than the fathers'.

4. The German interviews were conducted directly before (first round of interviews) and after (follow-up interviews) the 2007 reform, which introduced the so-called 'daddy months'. Thus, the fathers participating in our study were entitled to parental leave, but under less supportive conditions than fathers of children born in 2007 or later. In Italy, additional couples had been recruited for this edited volume, as some of the couples previously analysed had dropped out of the study. Due to policy changes introduced in 2012, these Italian couples enjoyed slightly more support for working fathers compared to their interviewed peers, including two days of paternity leave.

5. European means were calculated based on weighted mean values across all respondents of the 46 EVS countries and correspond to 22 for the promotion of fathers as carers and 18 for maternal employment.

6. Whereas this is the case in Sweden, other contexts such as Poland and the Czech Republic neither promote paternal care through family policies nor do they provide cultural support for caring fathers. In the case of Austria, fathers are to 
some extent framed as carers both in the cultural and policy realm, but to a lower extent than Sweden.

7. Studies show that fathers' uptake of paid leave has increased strongly from 3.5 per cent in 2006 to close to 30 per cent in 2016 (Bünning 2015, 2016) and that mothers now return to employment much sooner than before these reforms (Frodermann et al. 2013). These rapid cultural and behavioural changes are not yet reflected in our data but will be addressed more thoroughly in the German country chapter.

8. In Switzerland, paid leave is restricted to 14 weeks and is paid at 80 per cent of the income. This period is far below the time prescribed by the WHO for breastfeeding new-borns full-time (Butte et al. 2002). Working mothers thus not only struggle to find infant care but also to breastfeed their children in line with health care advice.

9. Please note that we hypothesized this gap to be 'small to medium' in the previous edited volume (Grunow and Veltkamp 2016, p. 21) and concluded the gap to be rather small (Evertsson and Grunow 2016, p. 272).

\section{REFERENCES}

Aisenbrey, S., M. Evertsson and D. Grunow (2009), 'Is there a career penalty for mothers' time out? A comparison of Germany, Sweden and the United States', Social Forces, 88 (2), 573-606.

Balbo, N., F.C. Billari and M. Mills (2013), 'Fertility in advanced societies: a review of research', European Journal of Population, 29 (1), 1-38.

Becker, G.S. (1981), A Treatise on the Family, Cambridge, MA: Harvard University Press.

Blood, R.O. and D.M. Wolfe (1960), Husbands and Wives: The Dynamics of Married Living, Glencoe: Free Press.

Blumberg, R.L. and M.T. Coleman (1989), 'A theoretical look at the gender balance of power in the American couple', Journal of Family Issues, 10 (2), 225-50.

Budig, M.J., J. Misra and I. Boeckmann (2010), 'The wage penalty for motherhood in a cross-national perspective: relationships with work-family policies and cultural attitudes', paper presented at Annual Meeting of the Population Association of America, Dallas, TX, 15 April.

Bühlmann, F., G. Elcheroth and M. Tettamanti (2010), 'The division of labour among European couples: the effects of life course and welfare policy on value-practice configurations', European Sociological Review, 26 (1), 49-66.

Bünning, M. (2015), 'What happens after the "daddy months"? Fathers' involvement in paid work, childcare, and housework after taking parental leave in Germany', European Sociological Review, jcv072.

Bünning, M. (2016), 'Die Vereinbarkeitsfrage für Männer: Welche Auswirkungen haben Elternzeiten und Teilzeitarbeit auf die Stundenlöhne 
von Vätern?', KZfSS Kölner Zeitschrift für Soziologie und Sozialpsychologie, 68 (4), 597-618.

Butte, N.F., M.G. Lopez-Alarcon and C. Garza (2002), Nutrient Adequacy of Exclusive Breastfeeding for the Term Infant During the First Six Months of Life, Geneva: World Health Organization.

Clausen, J.A. (1995), 'Gender, contexts, and turning points in adults' lives', in P. Moen, G.H. Elder, Jr. and K. Liischer (eds), Examining Lives in Context: Perspectives on the Ecology of Human Development, Washington, DC: APA Press, pp. 365-89.

Cooke, L.P. (2014), 'Gendered parenthood penalties and premiums across the earnings distribution in Australia, the United Kingdom, and the United States', European Sociological Review, 30 (3), 360-72.

Davis, S.N. and T.N. Greenstein (2009), 'Gender ideology: components, predictors, and consequences', Annual Review of Sociology, 35 (1), 87-105.

Edlund, J. and I. Öun (2016), 'Who should work and who should care? Attitudes towards the desirable division of labour between mothers and fathers in five European countries', Acta Sociologica, 59 (2), 151-69.

Elder, G.H. (1998), 'The life course as developmental theory', Child Development, 69 (1), 1-12.

England, P. (2016), 'Sometimes the social becomes personal gender, class, and sexualities', American Sociological Review, 0003122415621900.

Esping-Andersen, G. (1990), The Three Worlds of Welfare Capitalism, Princeton: Princeton University Press.

Esping-Andersen, G. (1999), Social Foundations of Postindustrial Economies, New York: Oxford University Press.

Evertsson, M. (2016), 'Institutional context, family policies and women's and men's work outcomes in eight European welfare states', in D. Grunow and M. Evertsson (eds), Couples' Transitions to Parenthood: Analysing Gender and Work in Europe, Cheltenham, UK and Northampton, MA, USA: Edward Elgar Publishing, pp. 34-61.

Evertsson, M. and D. Grunow (2016), 'Narratives on the transition to parenthood in eight European countries. The importance of gender culture and welfare regime', in D. Grunow and M. Evertsson (eds), Couples' Transitions to Parenthood: Analysing Gender and Work in Europe, Cheltenham, UK and Northampton, MA, USA: Edward Elgar Publishing, pp. 269-94.

EVS (2011), 'European values study 2008: integrates dataset (EVS 2008)', GESIS Data Archive, Cologne, ZA4800 data file Version 3.0.0, doi: 10.4232/1.11004.

Fox, B.J. (2009), When Couples Become Parents: The Creation of Gender in the Transition to Parenthood, Ontario: University of Toronto Press. 
Frodermann, C., D. Müller and M. Abraham (2013), 'Determinanten des Wiedereinstiegs von Müttern in den Arbeitsmarkt in Vollzeit oder Teilzeit', Kölner Zeitschrift für Soziologie und Sozialpsychologie, 65 (4), 645-68.

Grunow, D. (2014), 'Aufteilung von Erwerbs-, Haus- und Familienarbeit in Partnerschaften im Beziehungsverlauf. Der Einfluss von Sozialpolitik in Europa', in D. Lück and W. Cornelißen (eds), Geschlechterunterschiede und Geschlechterunterscheidungen in Europa, Stuttgart: Lucius, pp. 237-63.

Grunow, D. (2016), 'Comparing couples' narratives within and across countries: research design, sampling and analysis', in D. Grunow and M. Evertsson (eds), Couples' Transitions to Parenthood: Analysing Gender and Work in Europe, Cheltenham, UK and Northampton, MA, USA: Edward Elgar Publishing, pp. 62-76.

Grunow, D. (2017), 'Theoriegeleitetes Sampling für international vergleichende Mixed-Methods-Forschung: Ein Beispiel der Untersuchung von Normen und Praxis familiärer Arbeitsteilung', Kölner Zeitschrift für Soziologie und Sozialpsychologie, 69 (2), 213-35.

Grunow, D., K. Begall and S. Buchler (2018), 'Gender ideologies in Europe: a multidimensional framework', Journal of Marriage and Family, 80 (1), 42-60.

Grunow, D. and M. Evertsson (eds) (2016), Couples' Transitions to Parenthood: Analysing Gender and Work in Europe, Cheltenham, UK and Northampton, MA, USA: Edward Elgar Publishing.

Grunow, D. and G. Veltkamp (2016), 'Institutions as reference points for parents-to-be in European societies: a theoretical and analytical framework', in D. Grunow and M. Evertsson (eds), Couples' Transitions to Parenthood: Analysing Gender and Work in Europe, Cheltenham, UK and Northampton, MA, USA: Edward Elgar Publishing, pp. 3-33.

Gupta, S. (2007), 'Autonomy, dependence, or display? The relationship between married women's earnings and housework', Journal of Marriage and Family, 69 (2), 399-417.

Hodges, M.J. and M.J. Budig (2010), 'Who gets the daddy bonus? Organizational hegemonic masculinity and the impact of fatherhood on earnings', Gender \& Society, 24 (6), 717-45.

Johns, H.M., D.A. Forster, L.H. Amir and H.L. McLachlan (2013), 'Prevalence and outcomes of breast milk expressing in women with healthy term infants: a systematic review', BMC Pregnancy and Childbirth, 13 (1), 1.

Keck, W. and C. Saraceno (2012), 'Multilinks database on intergenerational policy indicators', Schmollers Jahrbuch, 132 (3), 453-61.

Killewald, A. (2012), 'A reconsideration of the fatherhood premium marriage, coresidence, biology, and fathers' wages', American Sociological Review, 0003122412469204. 
Klijzing, E. (2000), 'Are there unmet family planning needs in Europe?', Family Planning Perspectives, 32 (2), 74-81, and 88.

Lee, E., J. Bristow, C. Faircloth and J. Macvarish (2014), Parenting Culture Studies, Basingstoke: Palgrave Macmillan.

Levy, R., E.D. Widmer and J. Kellerhals (2002), 'Modern family or modernized family traditionalism? Master status and the gender order in Switzerland', Electronic Journal of Sociology, 6 (4), 1-42.

Lück, D. (2005), Cross-national Comparison of Gender Role Attitudes and their Impact on Women's Life Courses. Globalization, Uncertainty, and Women in Society, Cheltenham, UK and Northampton, MA, USA: Edward Elgar Publishing.

Lundberg, S. and R.A. Pollak (1996), 'Bargaining and distribution in marriage', The Journal of Economic Perspectives, 10 (4), 139-58.

Matysiak, A. and D. Vignoli (2010), 'Employment around first birth in two adverse institutional settings: evidence from Italy and Poland', Zeitschrift für Familienforschung, 22 (3), 331-49.

Miller, T. (2011), 'Falling back into gender? Men's narratives and practices around first-time fatherhood', Sociology, 45 (6), 1094-109.

Moen, P. (2003), 'Linked lives: dual careers, gender, and the contingent life course. Social dynamics of the life course', Transitions, Institutions, and Interrelations, Conference Proceedings, 237-58.

Moen, P. and M.A. Erickson (1995), 'Linked lives: a transgenerational approach to resilience', in P. Moen, G.H. Elder, K. Lüscher and U. Bronfenbrenner (eds), APA Science Volumes. Examining Lives in Context. Perspectives on the Ecology of Human Development, Washington, DC: American Psychological Association, pp. 169-210.

Morgan, K.J. (2006), Working Mothers and the Welfare State. Religion and the Politics of Work-Family Policies in Western Europe and the United States, Stanford, CA: Stanford University Press.

Naldini, M. and T. Jurado (2013), 'Family and welfare state reorientation in Spain and Inertia in Italy from a European perspective', Population Review, 52 (1), 43-61.

Nešporová, O. and R. Horňáková (2016), 'Constructions of parenthood in the Czech Republic: maternal care and paternal help', in D. Grunow and M. Evertsson (eds), Couples' Transitions to Parenthood: Analysing Gender and Work in Europe, Cheltenham, UK and Northampton, MA, USA: Edward Elgar Publishing, pp. 243-65.

Nitsche, N. and D. Grunow (2016), 'Housework over the course of relationships: gender ideology, resources, and the division of housework from a growth curve perspective', Advances in Life Course Research, 29, 80-94.

Nitsche, N. and D. Grunow (2018), 'Do economic resources play a role in bargaining child care in couples? Parental investment in cases of matching and 
mismatching gender ideologies in Germany', European Societies, Online first, doi: 10.1080/14616696.2018.1473626.

OECD family database (2017), LMF2.1 Usual weekly working hours among men and women by broad hours groups. OECD - Social Policy Division Directorate of Employment, Labour and Social Affairs, accessed October 2017 at www.oecd.org/els/family/database.htm.

Orloff, A.S. (2003), 'Markets not states? The weakness of state social provision for breadwinning men in the U.S.', in L. Haney and L. Pollard (eds), Families of a New World, New York: Routledge, pp. 217-45.

Pfau-Effinger, B. (2012), 'Women's employment in the institutional and cultural context', International Journal of Sociology and Social Policy, 32 (9), 530-43.

Reimann M. (2016), 'Searching for egalitarian divisions of care: Polish couples at the life-course transition to parenthood', in D. Grunow and M. Evertsson (eds), Couples' Transitions to Parenthood: Analysing Gender and Work in Europe, Cheltenham, UK and Northampton, MA, USA: Edward Elgar Publishing, pp. 221-42.

Risman, B. (2004), 'Gender as a social structure', Gender \& Society, 18, 429-50.

Rönkä, A., S. Oravala and L. Pulkkinen (2003), 'Turning points in adults' lives: the effects of gender and the amount of choice', Journal of Adult Development, 10 (3), 203-15.

Rønsen, M. and M. Sundström (2002), 'Family policy and after-birth employment among new mothers - a comparison of Finland, Norway and Sweden', European Journal of Population, 18 (2), 121-52.

Ruhm, C.J. (1998), 'The economic consequences of parental leave mandates: lessons from Europe', The Quarterly Journal of Economics, 113 (1), 285-317.

Saraceno, C. (2010), 'Social inequalities in facing old-age dependency: a bi-generational perspective', Journal of European Social Policy, 20 (1), $32-44$.

Saraceno, C. and W. Keck (2011), 'Towards an integrated approach for the analysis of gender equity in policies supporting paid work and care responsibilities', Demographic Research, 25, 371-406.

Schmidt, E., I. Rieder, U. Zartler, C. Schadler and R. Richter (2015), 'Parental constructions of masculinity at the transition to parenthood: the division of parental leave among Austrian couples', International Review of Sociology, 25 (3), 373-86.

Valarino, I. (2016), 'Les congés parentaux en Suisse: révélateurs de politiques et de représentations genrées', in J.-M. Le Goff and R. Levy (eds), Devenir parents, devenir inégaux. Transition à la parentalité et inégalités de genre, Zurich: Seismo, pp. 235-61. 
Wall, G. (2010), 'Mothers' experiences with intensive parenting and brain development discourse', Women's Studies International Forum, 33 (3), 253-63. 